\title{
Effect of instrumental response pretraining in classical-to- instrumental transfer of a differential reward magnitude discrimination'
}

\author{
CHARLES F. FLAHERTY ${ }^{2}$ and JOHN W. \\ DA VENPORT, Regional Primate Research \\ Center, University of Wisconsin, Madison, \\ Wis. 53706
}

Amount of preliminary bar-press training (25 vs 125 discrete fixed-ratio trials) and amount of noncontingent pretraining $10 \mathrm{vs}$ 500 presentations of cues and associated reward magnitudes with the lever retracted) were manipulated factorially prior to contingent discrimination between five-and one-pellet cues. The 500-presentation groups demonstrated differential responding in start speed earlier in the contingent phase than the 0-presentation groups, confirming previous findings of classical-toinstrumental transfer of the discrimination. The major effect of the lever pretraining was a higher small-reward start speed in the 125-trial groups than in the 25-trial groups. Ratio speed data differed markedly from start speed data in showing large differences in favor of one-pellet ratio speeds early in training and very little evidence of five-over one-pellet discrimination late in training.

In a previous report (Flaherty \& Davenport, 1968) it was shown that acquisition of an instrumental discrimination based on differential reward magnitude in a discrete-trials lever-pressing situation can be greatly facilitated by prior noncontingent exposure to the discriminative cues (click vs flashing light) and associated reward magnitudes (five vs one pellet). It was also shown that as the number of prior noncontingent trials (during which the lever is retracted) is increased from 0 to 200 , progressively greater facilitation of the subsequent contingent discrimination is found.

It was not clear from these data whether the 200-trial condition represented the maximum degree of facilitation that is possible in this transfer situation. In the present study we have included a 500-trial condition to investigate further the limits of transfer, and have used animals and testing conditions as nearly identical to those of the previous studies as possible for the sake of valid comparisons between studies. In the present experiment we have also studied the effect of varying amount of initial instrumental training in which discrete-trials lever-pressing is established prior to the introduction of the differential cues and reward magnitudes constituting the discrimination conditions.

\section{SUBJECTS}

The Ss were 32 naive male albino rats of the Holtzman strain, approximately 100 days old at the beginning of the experiment. The Ss were maintained at $80 \%$ of their ad lib weight on a once-a-day feeding schedule which was begun 11 days prior to pretraining.

\section{APPARATUS}

Two Gerbrands Model C test chambers described previously (Flaherty \& Davenport, 1968) were used without change. Each was enclosed in a picnic ice chest and equipped with a Lehigh Valley retractable lever mounted directly under a cue light, a ceiling-mounted houselight, a 45-mg pellet dispenser, a recessed foodcup, and a relay which produced a clicking sound when energized by a 10/sec pulse stream. PROCEDURE

Except for manipulation of the independent variables the procedure was essentially identical to that used in the previous study. The various training phases consisted of (a) magazine training, (b) free-operant lever training, (c) discrete-trial lever training, (d) noncontingent discrimination training, and (e) contingent discrimination training. The experimental factors were varied in phases (c) and (d).

Magazine training(Day 1) consisted of 60 pellets delivered on a variable-interval (VI) 30-sec schedule. In free-operant lever training (Day 2) the Ss were required to make 20 continuously reinforced (CRF)

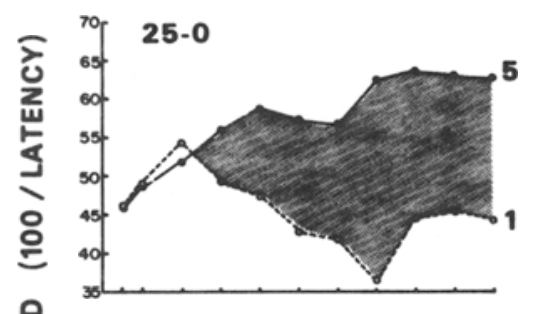

barpresses. Transitional discrete-trials training, from CRF to fixed-ratio 5 (FR 5), was given on Day 3. Each $S$ was required to complete one (Trials 1-5), two (Trials 6-10), three (Trials 11-15), and five (Trials 16-20) barpresses per trial. Trial onset was signaled by insertion of the lever and lighting of the houselight. When the response was completed a single pellet reward was delivered and the lever was retracted. The houselight remained on for $10 \mathrm{sec}$ after delivery of the reward. The intertrial interval was a VI $30 \mathrm{sec}$. For a random half of the Ss one additional 20-trial session on FR 5 was given. The remaining $S s$ received six additional 20-trial FR 5 sessions. These operations ( 25 vs 125 FR 5 pretraining trials) defined the levels of the first independent variable.

Half of each of the above groups (Subgroups 25-0 and 125-0) received no noncontingent training. The remaining subgroups (25-500 and 125-500) received 500 noncontingent discrimination trials in 25 20-trial sessions. On noncontingent trials the discriminative stimuli (flashing cue light or click) and the rewards (one or five pellets) were presented with the lever retracted from the response chamber. The pairing of stimuli with reinforcement levels was counterbalanced and confounded with chambers. On a noncontingent trial houselight onset, stimulus onset, and operation of the pellet dispenser were simultaneous. The stimulus and houselight remained on for $10 \mathrm{sec}$. The
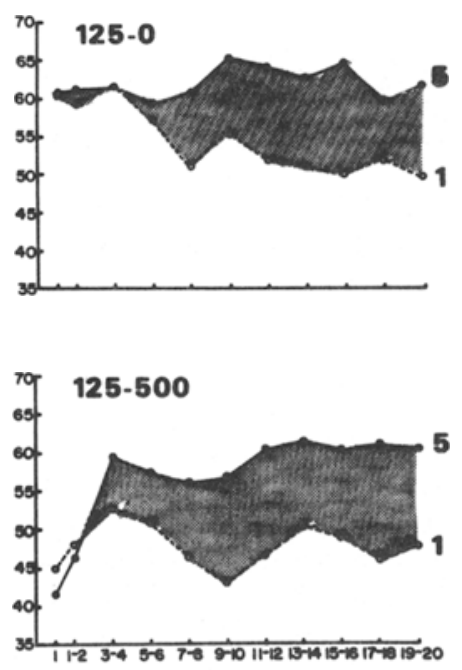

DAYS

Fig. 1. Mean start speed curves of the four groups in the contingent discrimination phase. The shading indicates discrimination in terms of greater five- than one-pellet speed. 

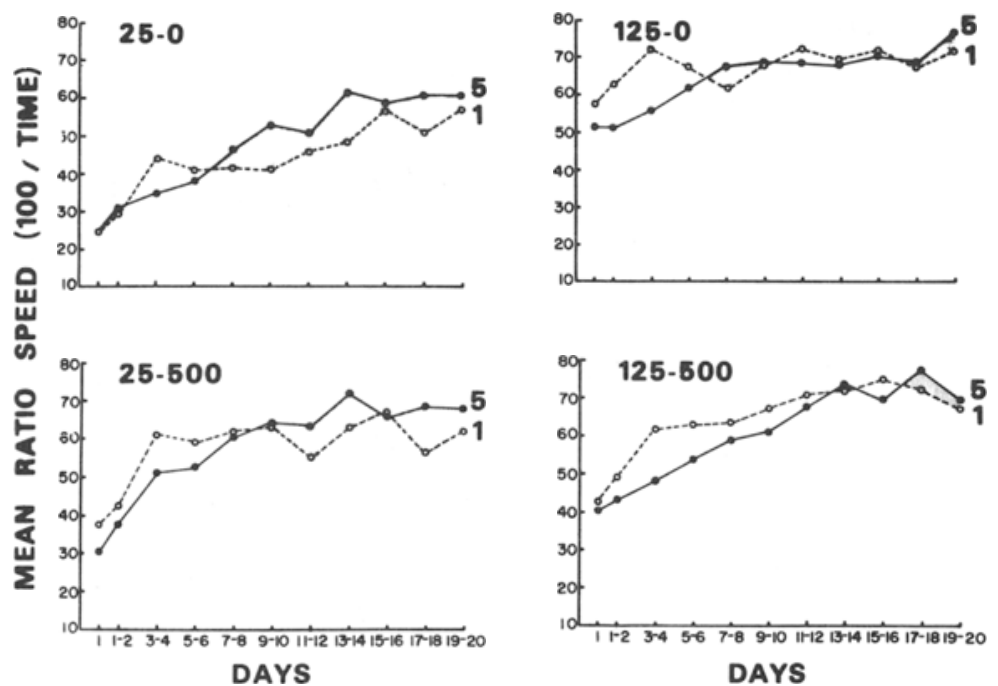

DAYS

Fig. 2. Mean ratio speed curves of the four groups in the contingent discrimination phase.

intertrial interval was a VI $30 \mathrm{sec}$. The sequence of 10 five-pellet trials and 10 one-pellet trials within a session followed a Gellermann series. Four different Gellermann series were used across days.

The final contingent discrimination phase began on the day following barpress training for the 25-0 and 125.0 subgroups and on the day following noncontingent training for the 25-500 and 125-500 subgroups. In this phase reinforcement was contingent upon completion of five barpresses. Measures of first-response latency (reciprocalized to start speed) and time from the first to the fifth barpress (reciprocalized to ratio speed) were recorded. Trial onsets were signaled by extension of the lever and onset of cue and houselight. Upon completion of the five responses the lever was retracted and the appropriate reward delivered. The cue and houselight remained on for $10 \mathrm{sec}$ after delivery of the reward. Twenty 20-trial sessions were administered in this phase, with the intermixture of five-and one-pellet trials governed by four different Gellermann series. The relationship of cues to reward magnitudes was unchanged from that of the noncontingent phase.

\section{RESULTS \\ Start Speed}

The course of contingent discrimination as gauged by the start speed measure is presented in Fig. 1. All four subgroups clearly discriminated and the 500-presentation subgroups (lower panels) showed an earlier formation of the discrimination than the 0-presentation subgroups (upper panels). This effect was statistically represented by a significant Noncontingent Trials by Day by Magnitude interaction $(F=1.82$, $\mathrm{df}=19 / 456, \mathrm{p}<.05)$. Subsequent tests using Fisher's lsd procedure showed significant $(p<.05)$ evidence of discrimination developing as early as Day 3 for the 500-presentation subgroups whereas the 0 -presentation subgroups did not reveal significant superiority of five- over onepellet start speed until Day 6.

In the overall analysis, the amount of lever pretraining did not interact significantly with the development of the discrimination (Lever Training by Day by Magnitude, $F=1.28, \mathrm{df}=19 / 456, \mathrm{p}>.05$ ), nor did it interact with the influence of the noncontingent presentations on discrimination development (Lever Training by Noncontingent Trials by Day by Magnitude, $F<1.00)$. A more sensitive analysis of one-pellet speeds only, however, showed that the 125-trial subgroups were significantly faster than the 25-trial subgroups $(F=4.56, d f=1 / 24, p>.05)$. There were no significant interactions with days or noncontingent trials.

\section{Ratio Speed}

The ratio speed data (Fig. 2) differed markedly from the start speed data in that the 125-trial subgroups (right panels) showed no evidence of a five-pellet over one-pellet discrimination and the 25-trial subgroups showed only a small trend in this direction. In addition, all four subgroups displayed greater one-pellet than five-pellet ratio speed early in training.

In an analysis of variance on the ratio speed data the initial superiority of the one-pellet speeds was reflected in a Day by Magnitude interaction $(F=6.21$, $\mathrm{df}=19 / 456, \mathrm{p}<.01)$. Subsequent analysis of this term using the lsd procedure $(\mathrm{p}=.05$, two-tail) showed that the one-pellet speeds were significantly faster than the five-pellet speeds on Days 2-5, whereas five-pellet speeds were faster than one-pellet speeds on Days 13, 17, and 19. There was no significant interaction of the Day by
Magnitude term with either the lever training or noncontingent trials variables. However, a tendency for increased lever training to inhibit a discrimination in terms of faster five- than one-pellet ratio speeds was reflected in a significant Lever Training by Magnitude interaction $(F=6.12$, $\mathrm{df}=1 / 24, \mathrm{p}<.05)$.

\section{DISCUSSION}

The previous findings (Flaherty \& Davenport, 1968) of noncontingent-tocontingent transfer of a differential reward magnitude discrimination were confirmed and extended in the present study. Judging from comparison of the 500-presentation subgroups of this experiment with the 0 -, $20-$, and 200-presentation groups of the earlier research, the limit to which formation of an instrumental discrimination of this type can be facilitated is reached with approximately 200 noncontingent pairings. More importantly, the point of apparent maximum transfer falls short of immediate discrimination on Day 1 of the contingent phase, which supports our earlier interpretation that some components of the behavioral chains required for appropriate performance in the final discrimination phase must be learned in that phase even though important components may be acquired in the noncontingent phase.

The amount of lever pretraining did not influence the point at which discrimination developed in either the 0 - or 500-presentation subgroups. The only significant effect of the lever-training variable was an overall higher level of small-reward speeds in the 125-trial groups. This finding is compatible with recent data (Platt \& Gay, 1968;Spear \& Spitzner, in press) indicating that the negative contrast effects characteristic of within-Ss manipulation of reward magnitude may not appear if extensive prior experience with the small reward is given.

A disparity between start and ratio speed measures has been a consistent finding in our research with a discrete fixed-ratio task (Flaherty, 1968; Flaherty \& Davenport, 1968; Davenport \& Flaherty, 1969). The start speed measure has regularly shown clear five-over-one-pellet discrimination, but the ratio speed measure has typically revealed consistent superiority of smallreward speeds early in training followed by a convergence or very small differences in favor of the large-reward speeds. In the present experiment this disparity was especially clear, with all four subgroups showing large five-over-one-pellet start speed differences and temporary superiority of one-over-five-pellet ratio speed early in training. In the case of the 125-500 subgroup the small-reward ratio speed superiority approached the inverse pattern of performance of rats in differential magnitude discrimination in black and white 
runways reported by MacKinnon \& Russotti (1967), in which with 2:1 magnitude ratio, run and goal speed measures showed small-reward superiority throughout training. It is tempting, particularly in view of the possibility of accounting for the fasterrunning-to-small-reward effect in terms of energizing effects of frustration (Amsel, 1967), to summarize this disparity between measures by the statement that start speed tends to reflect inhibitory effects while ratio speed tends to reveal energizing effects. In the present discrete lever-pressing situation, however, it must be noted that the one-over-five-pellet ratio speed difference may at least partly reflect the operation of an interfering response of approaching the foodcup prior to completing the ratio requirement on large-reward trials.

\section{REFERENCES}

AMSEL, A. Partial reinforcement effects on vigor and persistence: Advances in frustration theory derived from a variety of within-subjects experiments. In K. W. Spence and J. T. Spence (Eds.), The psychology of learning and motivation: Advances in research and theory. Vol. 1. New York: Academic Press, 1967.
DAVENPORT, J. W. \& FLAHERTY, C, F Extinction of differential reward magnitude discrimination in a discrete bar-pressing situation. Psychonomic Science, 1969, 14, 29-30.

FLAHERTY, C. F. Interactive effects of reward magnitude in two- and three-stimulus discriminations. Unpublished doctoral dissertation, University of Wisconsin, 1968.

FLAHERTY, C. F., \& DAVENPORT, J. W Noncontingent pretraining in instrumental discrimination between amounts of reinforcement. Journal of Comparative \& Phy siological Psychology, 1968,66, 707-711.

MacKINNON, J. R., \& RUSSOTTI, J.S. An inverse performance pattern in a discrimination based on differential magnitudes of reward. Psychonomic Science, 1967, 7, 395-396.

PLATT, J. R. \& GAY, R. A. Differential magnitude of reward conditioning as a function of predifferential reward magnitude. Journal of Experimental Psychology, 1968, 77, 393-396.

SPEAR, N. E., \& SPITZNER, J. H. The influence of degree of training and prior reinforce magnitude on contrast effects and resistance to extinction within S. Joumal of Comparative \& Phy siological Psychology, in press.

\section{NOTES}

1. Supported by Grant FR-00167 from the National Institu tes of Health

2. Now at Rutgers, The State University, New Brunswick, N.J.

elsewhere (Kellicutt, 1967). Basically, it consisted of a $5 \times 12 \times 8$-in. cage enclosed in a ventilated plywood and Masonite box. One inch from the cage floor was a liquid delivery fountain contained within a recess in the front wall. When activated, the system would deliver approximately $.02-\mathrm{ml}$ water reinforcements. The manipulandum itself consisted of a Plexiglas rod $3 / 16$ in. in diam terminating in an aluminum knob $5 / 8$ in. in diam. Ss were required only to make a $1 / 8$-in. pull with a force of about $18 \mathrm{~g}$ to activate the programming and recording equipment. The maximum possible excursion of the plunger was 2 in. Reinforcement, when available, did not occur until the plunger was returned to the home position. Therefore no reward cues were present during the response. The plunger was located 2 in. from the fountain at floor level and in the right hand corner of the cage. It was separated from the fountain by a 1-in.-high brass partition which effectively limited responses to the right forepaw. A $4 \times 5$-in. white translucent screen located directly above the water fountain was illuminated from behind with nine 24-V bulbs. Summed response durations and frequencies were recorded on separate timers and counters as a function of whe ther or not they were reinforced.

\section{EXPERIMENT}

Procedure

\section{Response duration differentiation during fixed ratio responding}

\author{
M. H. KELLICUTT and PHILIP $M$. \\ SALZBERG, University of California, \\ Davis, Calif. 95616
}

Eight albino rats were trained to pull a plunger for water reinforcements that were delivered on several fixed ratios from $F R-4$ to FR-32. The mean durations of the nonreinforced responses in the FR chain were significantly longer than mean reinforced durations. This differentiation also proved to be labile to exteroceptive stimulus cues.

A number of studies dealing with the intensive properties of the operant response have revealed that response durations are always greater during nonreinforced conditions, e.g., extinction and $S \Delta$ periods of a discrimination (Kellicutt, 1967). The present study is an attempt to demonstrate this same effect during fixed-ratio schedules of reinforcement. In their study of different FI and $F R$ reinforcement schedules, Millenson, Hurwitz, \& Nixon (1961) failed to find any orderly response differentiation, based on duration within an FR chain. Perhaps one explanation to account for this is that the manipulandum they employed did not provide sufficient "response availability."1 In their apparatus, "A 3-gram downward force applied to the lever acting through 1 millime ter closed a microswitch." In view of the fact that response duration and amplitude are closely correlated, a system which permitted only minimum movement of the manipulandum would naturally reduce response variability; hence a reduction in the differentiation of response topographies.

Mintz (1962), however, has demonstrated that Wistar rats will show response differentiation between the reinforced and nonreinforced components of an FR schedule if peak force is measured. It appears that response durations should follow the same trends as response force in spite of the results of the Millenson study.

\section{METHOD}

The Ss were eight male albino rats of the Sprague-Dawley strain, approximately 125 days old. Each had served in the same condition of a previous acquisition extinction study. 1 Their water ration was provided only by the experimental sessions.

The apparatus has been described in de tail
Each of the five Ss in this experiment were run daily for 1-3 h. Ss were run on an FR-4 schedule for 34 days. As soon as response rates became stable the schedule was changed to FR-8. Ss were run 4-5 days at FR-8 again until rates stabilized, and the schedule was shifted to FR-16. Similarly, after 5-11 days at FR-16, an FR-32 schedule was initiated. The experiment was terminated after 4-11 days at FR-32.

Results

Although terminal response rates were never terribly high (e.g., the mean terminal rate at FR-32 was 28.7 responses/min), cumulative records collected during each session showed the "scalloping" typical of FR performance. The mean response durations for each reward condition collected for the last 2 days at each schedule value appear in Fig. 1. An analysis of variance performed on these data indicates that overall nonreinforced durations were significantly longer than reinforced values $[F(1,4)=7.73, p<.05]$. The analysis detected no significant overall trend across schedule values nor any interaction of schedule value and reward condition. Clearly, then, FR reinforcement schedules can give rise to differential mean response duration emission.

\section{EXPERIMENT 2}

Procedure

To control for the possibility that the 